\title{
Histochemical Investigation on the Chondrosulfatase in the Sweat Glands of the Human Axilla
}

\author{
By \\ Hisakazu Ohmura and Toshio Yasoda \\ Department of Anatomy, School of Medicine, Keio University, Tokyo, Japan \\ (Director: Prof. Dr. T. Tan i u chi)
}

\section{Introduction}

Histochemical investigations on the sweat glands have been carried out by Schelley and Mescon (1952) on man and $\mathrm{Ka} \mathrm{ma-}$ mura (1954) on the cat. The authors have detected the sulfatase from the human sweat glands and obtained an interesting finding about the chondrosulfatase. Chondroitinsulfuric acid is an important ingredient of the connective tissues, that is, a large quantity of the chondroitinsulfuric acid is contained in such mesenchymal system as cartilage, bone, tendon, ligament, fascia, pericardium and the wall of blood vessels, and it is a principal component of glycoprotein.

With respect to the biochemical investigations, since $\mathrm{B}$ e d i c k e$r$ (1854) has initiated this investigation, the constitutional formula of chondroitinsulfuric acid was given through $\mathrm{S} \mathrm{ch} \mathrm{m}$ i e d e be r g (1891), Levene (1913) and Me yer (1946). Moreover, with the advance of the investigation on glycoprotein, the problem for chondroitinsulfuric acid is being clinically attached, too. This ferment, that is, chondrosulfatase was extracted for the first time from some kind of bacterium by $\mathrm{Neuberg}$ and $\mathrm{H}$ of $\mathrm{fmann}$ (1937). Thereafter, L illi e (1950) has succeeded in its extraction from the testicles. This ferment is $\mathrm{pH} 7$, resolves chondroitinsulfuric acid and not only extricates sulfuric acid but also reduces carbohydrate compound into sugar. Moreover, this ferment also resolves mucoitin-sulfate. As regards the histochemical demonstrating method for chondrosulfatase, $\mathrm{M} \mathrm{ochiz} \mathrm{uki}$ (1954) has reported for the first time using the albino rats. 


\section{Material and methods}

The material employed in this experiment was the skin in the axilla of man who has an odor under his arms. Immediately after the excision by surgical operation, the material was fixed with cold acetone for 24 hours, penetrated with benzol, embedded in paraffin at $50^{\circ} \mathrm{C}$ or less degrees and sectioned at $5 \mu$ in thickness. Thereafter the sections, through the washing for deparaffin, were immersed in the substrate solution for 24 hours. M o c h i z u k i's method was employed as the staining procedure. Namely the sections. just after the washing with water, were passed for a moment through $1 \%$ acetic acid solution to wash off commonly stained lead, and then immersed in diluted yellow ammonium sulfide for several minutes. After the changing of colour, the sections are again washed with water, dehydrated, run through xylol and enclosed in Bioleit. Positive activity demonstrates brown black coloration.

\section{Original findings}

In the cytoplasm the portion that faces the glandular lumen, the nucleolus and the cytoplasm of the myoepithelial cells generally exhibit an intensive reaction. On the surface of the glandular lumen, in the apocrine sweat glands, a cap-like and semicircular intensive reaction is found at the regions corresponding to the socalled "Burstensaum" and "Kruste" (Figs. 1, 2). Some of the reaction are observable as the figures that release towards the glandular lumen or that show zonal or linear types (Figs. 8, 10). In the eccrine sweat glands the reaction is observable in zonal type.

The secretory process shows a considerably intensive activity in the cap-like projected process (Figs. 3. 4), but the activity is diminished and becomes negative in proportion to the extension of the process (Figs. 6, 13). The cytoplasm shows a medium intensity in the activity and in the apocrine sweat glands the portion below the nucleus shows more intensive activity than the portion above the nucleus does, especially it is very remarkable at the basal portion. The activity at the portion above the nucleus is somewhat intensively recognizable around the secretory granules, vacuoles and the figure which is thought to be the Golgi zone (Figs. 1, 6).

In the eccrine sweat glands, the activity of the superficial cells is extremely intensive, on the contrary, that of the basement cells 
is very weak (Figs. 19, 20). However, not any differences of the activity between the portions above and below the nucleus are recognizable. The reaction of the nucleus generally is weak, especially in the eccrine sweat glands the activity of the nucleous is unclear, though in the apocrine sweat glands, the nucleous which shows an intensive activity is observable in the white cytoplasm as if it is an eye bulb (Figs. 1, 2). In the apocrine sweat glands where the secretory process is markedly projected, the karyoplasm itself shows relatively intensive activity (Figs. 13, 14). All nucleoli show remarkable activity. The nuclear membrane exhibits a somewhat more intensive activity than the karyoplasm. The cytoplasm of the myoepithelial cell shows an extremely intensive activity and presents a chessboard appearance (Figs. 5, 6) or zonal appearance (Figs. 9, 10). The same figures as mentioned above are observed in the eccrine sweat glands (Figs. 23, 24).

The boundary portion between the cells is weak in the activity. In the apocrine sweat glands, the activity in that portion is negative and in the eccrine sweat glands it is unclear. In the outer layer of myoepithelial cells, a filamentous structure which hardly shows activity is observable and in the more outer layer, another filamentous structure which shows an activity of medium intensity is recognizable. Namely, in the basement membrane, two layers, outer and inner, are distinguishable one from another because of the activity of sulfatase (Figs. 10, 14, 21). In the excretory ducts, the cells of the inner layer show a remarkable and intensive activity, while those of the outer layer show a.weak activity, and the activity of the karyoplasm is less intensive than the cells of both layers. But the nucleous shows an intensive activity.

\section{Discussions}

1. On the difference of the activity between the superficial and basement cells.

I t o (1943) has recognized two kinds of the cells, dark cells and clear ones, in the glandular corpus of the eccrine sweat gland, and he has insisted that the eccrine sweat gland is composed of two rows of cells. Thereafter, differences between the two types of the glandular cells in the eccrine sweat gland have been histochemically demonstrated by such many reactive methods as the reactions of alkaline and acid phosphatase, esterase ( $\mathrm{M}$ on ta g n a, 1956), phosphorylase 
and PAS routines. Even in the authors' findings on sulfatase, the superficial cells showed an intensive reaction but the basement cells did a weak. This fact, compared with the others' findings mentioned already, clearly shows the existence of two types of the glandular cells.

2. On the PAS positive substance and sulfatase.

As it is well known, the PAS positive substance is mostly observable at the portion that faces the glandular lumen of the apocrine sweat glands and in the secretory granules, on the other hand, in the eccrine sweat glands it is more often recognizable in the basement cells than in the superficial cells. The findings on sulfatase are in accordance with the findings on polysaccharides in the apocrine sweat glands but in the eccrine sweat glands the opposite findings are present as well as on alkaline phosphatase. Generally in this study, the findings alike those on acid phosphatase are recognized. But it is uncertain why they are.

3. On the basement membrane.

There are two different opinions that the basement membrane consists of two layers or three layers. According to M o n t a $\mathrm{na}$ (1956), the basement membrane is thought to consist of two different structures in either case where the basement membrane is examined with ammonia silver nitrate or with PAS. On the PAS reaction the basement membrane shows an intensively reacted inner layer and a weakly reacted outer layer, while on the reaction of sulfatase it reversely shows the reaction, that is, the inner layer of the basement membrane shows a weak, and the outer layer does an intensive reaction. Namely in the basement membrane the portion where the PAS positive substance exists is not in accordance with the portion where sulfatase reacts. In the PAS reactive portion, the reaction of sulfatase is not recognizable but in the PAS negative portion the reaction of sulfatase is recognizable. These facts surely prove that the portion where the PAS reaction for polysaccharides is recognizable, is not in accordance with the portion where the reaction of sulfatase which resolves polysaccharide-sulfatase is recognizable. It seems to the authors, that as the reason for the disagreement of the reactive portions, presence of sulfuricgroup has to do with.

\section{Conclusion}

1. The activity of chondrosulfatase in the sweat glands is the 
most intensive in the cytoplasm that faces the glandular lumen, nucleolus and myoepithelial cells. The basement membrane shows a medium intensity in activity and the boundary portion between the cells, karyoplasm and secretory process exhibit the weakest activity.

2. In the eccrine sweat glands, the activity in the superficial cells is very intensive, but that in the basement cells is weak. In the apocrine sweat glands the cytoplasm below the nucleus, especially at the basement shows more intensive activity than that above the nucleus.

3. The excretory ducts are divided in two layers, outer and inner layers, and the cells in the inner layer show very intensive activity but the cells in the outer layer show weak activity.

4. The karyoplasm, generally, is very weak in activity, or shows no activity.

5. The basement membrane is divided in two layers, inner and outer ones, the former shows weak, and the latter shows intensive activity.

6. The intensity of the activity in various portions of the sweat glands is as follows :

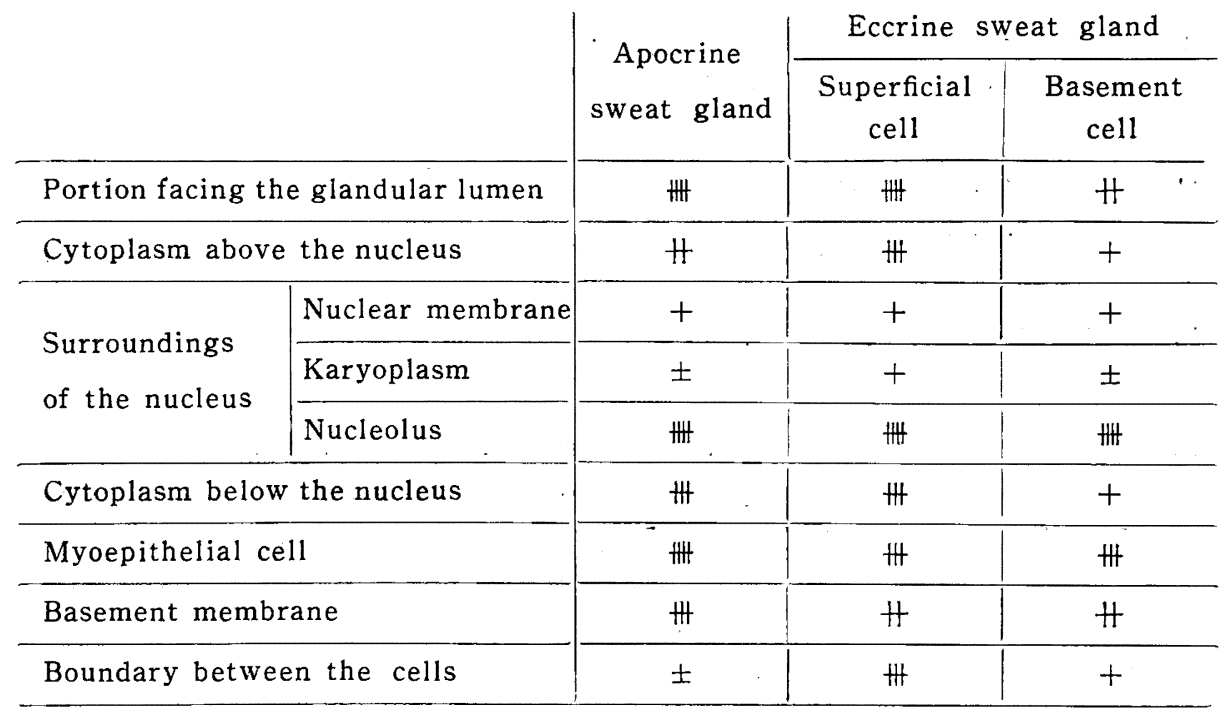

冊 extremely intensive activity.

\# intensive activity.

\# medium activity.
+ weak activity.

\pm very weak activity. 
In conculusion the authors wish to express their deep-felt thanks to Prof. Dr. T. Tanig u $\mathrm{ch}$ i for his criticism.

\section{Literatures}

1. It o, T.: Cytological studies of eccrine sweat gland. Igaku-no-shimpo, 6: 106, 1947.

2. I to, T. and K. I w a.sh ige: Zytologische Untersuchungen über die ekkrinen Schweissdrüsen in menschlicher Achselhaut mit Berücksichtigung der apokrinen Sekretion derselben. Okajimas Fol. anat. jap., 23: 174, 1951.

3. Ito, T. and K. Ooishi: Cytological study on the human eccrine sweat gland with special reference to its apocrine secretion. Kaibo Z., 23: 48, 1947 (in Japanese).

4. Kamamura, K.: Cytological study of cat sweat glands. "Okajimas Fol. anat. jap., 30: 1956.

5. Kraut, H. und A. We ischer: Sulfatasen, Physiologische Chemie (Flaschenträger u. Lahnart). 1: 1951.

6. Lilli e, R. D., E. W. Emmorf and A. M. Laskey: Chondromucinase from bovine testis and the chondromucine of the umbilical cord. Arch. pathol., 52(4): 363-368, 1954.

7. Mochizuki, N.: Histochemical demonstration of chondrosulfatase. Tokyo Iji-Shinshi, 73(2): 1956 (in Japanese).

8. Montagna, W.: The structure and function of skin. Academic press inc., New York, 1956.

9. $\mathrm{Neuberg}, \mathrm{C}$. und E. Hof $\mathrm{f} m$ a $\mathrm{n} n$ : Enzymatischer Abbau von Chondroitin Schwefelsaüre. Bioch. Z., $234: 345-346,1931$.

10. Ohara, M. and J. Kurata: Histochemical demonstration of sulfatase. Igaku-to-seibutsugaku, 16(4): 213-215, 1950 (in Japanese).

11. Oppenheimer, C.: Chondrosulfatase, die Fermente und ihre Wirkungen. Supp. Bd. 1, 172, Haag, 1936.

12. Seligman, A. M., M. M. Nach las s and R. Cohen: Histcchemical demonstration of glucurondase and sulfatase. Cancer Res., 10(4): 240, 1950.

13. Schelle y, W. D. and H. Mescon: Histochemical demonstration of secretory activity in human eccrine sweat gland. J. Invest. Dermatol., 18, 289-301, 1952.

14. M i y a $z$ a ki, T.: Biochemical studies on carbohydrates. IX. On the Fermentation of Chondroitin Sulfuric Acid by B. Pyocyaneus and on Pyocyarine. The J. of Biochem., Vol. 20, 287, 1934. 


\section{Explanation of figures}

1. 2. Semicircular intensive activity and starlightfeature at the portion that faced the glandular lumen. Positive features at the portion below the nucleus especially at the base. Weak activity in the karyoplasm and negative figure at the all around boundary.

3. 4. Positive feature of initial secretory process. Vacuoles in the cytoplasm above the nucleus. Extremely intensive activity in the nucleolus. Positive feature in the basement membrane.

5. 6. Extremely intensive activity in the myoepithelial cell.

7. 8. Intensively positive feature in the basement and positive feature in the secretory process at the initial stage.

9. 10. Zonal positive features at the portion that faced the glandular lumen and in the myoepithelial cell.

11. 12. Remarkable contrast between the inner layer and outer one of the exsecre tory duct.

13. 14. Negative feature in the developed secretory process and positive feature in the karyoplasm.

15. 16. Difference in the activity of the cells and positive feature in the myopeithelial cells.

17. 18. Filamentous positive feature at the portion that faced the glandular lumen.

19. 20. 21. 22. Eccrine sweat gland. Intensively positive feature at the portion that faced the glandular lumen. Intensively positive feature in the superficial cell and weak positive feature in the basement cell.

23. 24. Intensive, positive and chessboard feature in the myoepithelial cell. 
Plate I


H. Ohmura \& T. Yasoda 
Plate II
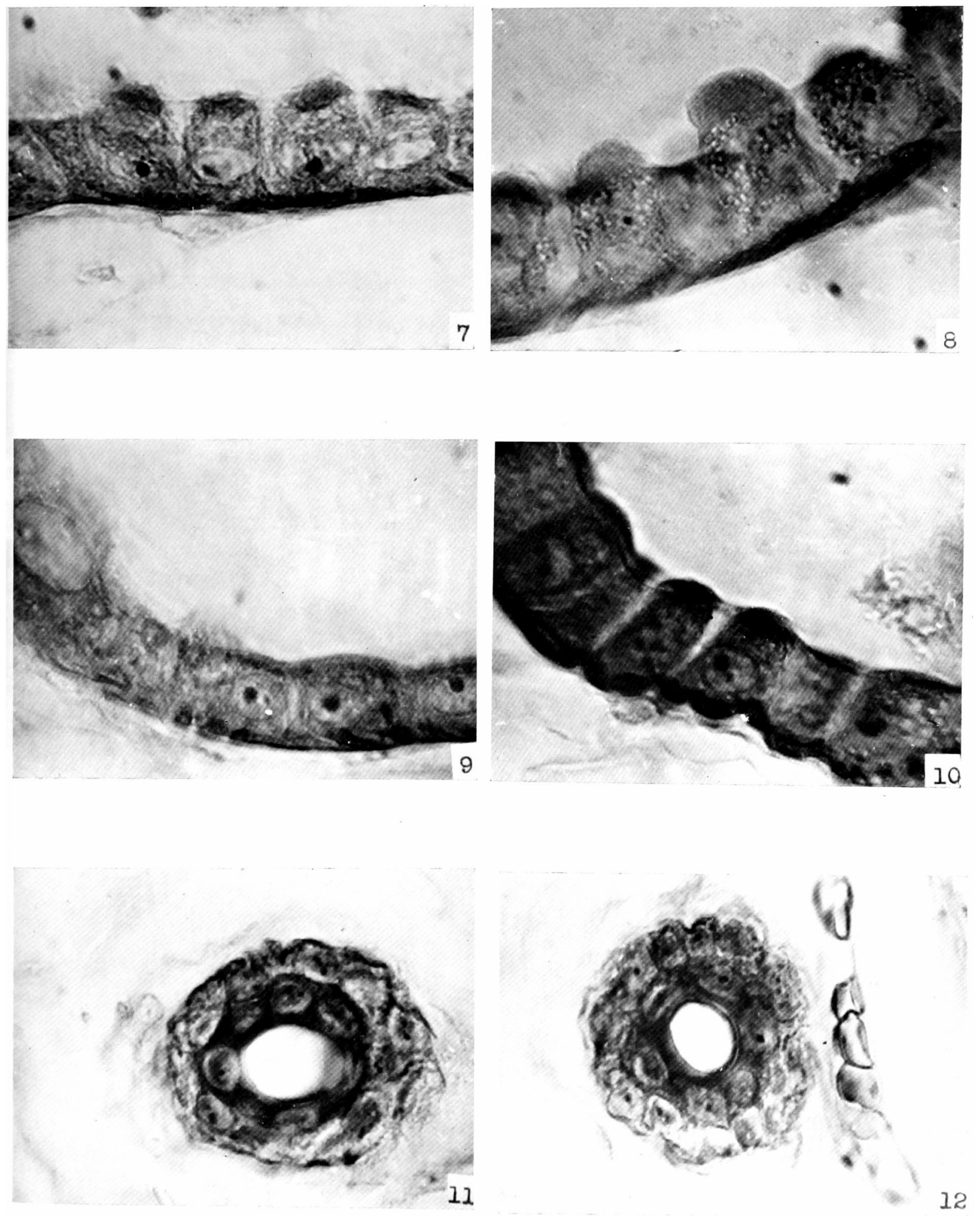

H. Ohmura \& T. Yasoda 
Plate III
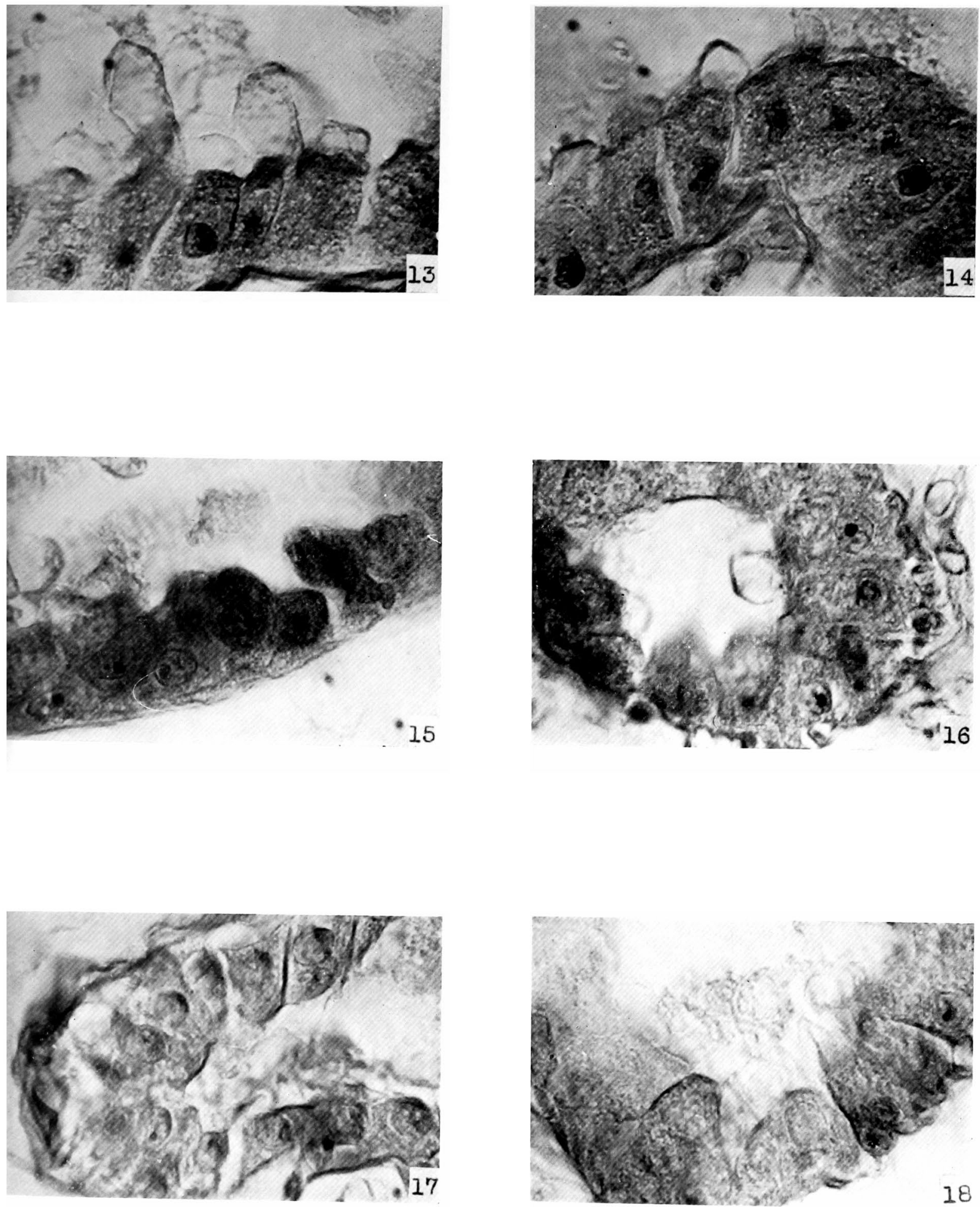

H. Ohmura \& T. Yasoda 


\section{Plate IV}
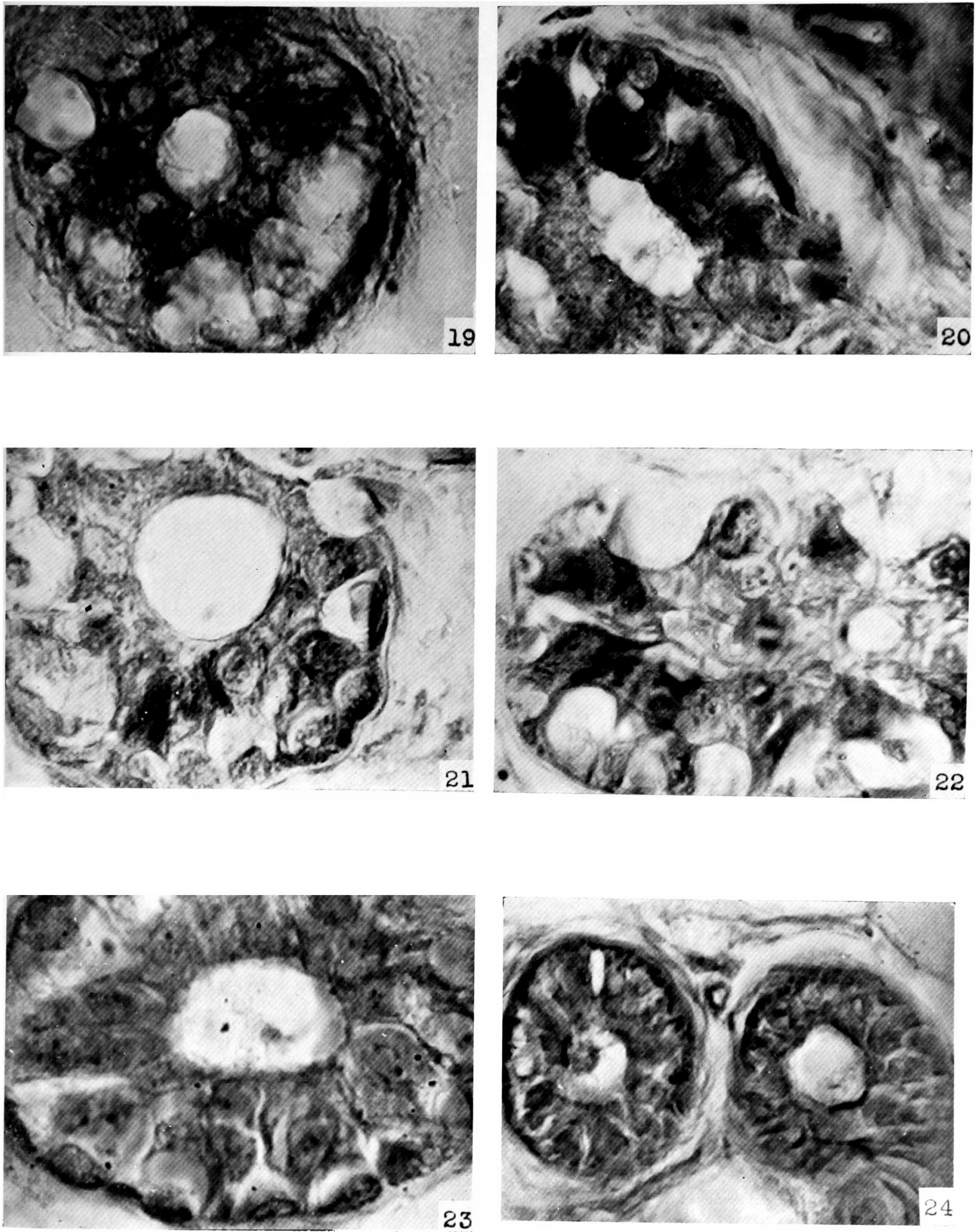

H. Ohmura \& T. Yasoda 